Artigos/Articles

\title{
Language issue in the 2lst century and the centuries ahead: an exercise in crystal-ball gazing
} A questão da linguagem no século XXI e nos outros ainda por vir: um exercício de olhar na bola de cristal

Kanavillil Rajagopalan'

\section{ABSTRACT}

Written in a speculative spirit, this paper is an attempt to take a peek into what the future might hold for the study of language. It takes into account the phenomenal changes that the world has undergone since the days when modern linguistics constituted itself as an academic discipline. It is argued that these changes call for a radical rethinking of some of the fundamental assumptions about language that have hardly ever been questioned until now.

Keywords: Modern Linguistics; $19^{\text {th }}$ century Zeitgeist; globalization; rethinking language.

1. Universidade Estadual de Campinas. Campinas, São Paulo - Brasil. https://orcid. org/0000-0003-3877-4936. E-mail: rajagopalan@uol.com.br 


\section{RESUMO}

Escrito num espírito especulativo, este trabalho é uma tentativa de dar uma espiada no que o futuro poderia estar guardando para o estudo da linguagem. Ele leva em conta as mudanças fenomenais que o mundo vem sofrendo desde os tempos em que a linguística moderna se constituiu como a uma disciplina acadêmica. Argumenta-se que essas mudanças demandam um repensar radical sobre algumas das assunções sobre a linguagem que quase nunca têm sido submetidas a um exame crítico.

Palavras-chave: Linguística Moderna; Zeitgeist do século XIX; globalização; repensar a linguagem.

\section{Warming up}

It is not for nothing that linguistics has been called a $19^{\text {th }}$ century discipline (Hutton, 1996). The very idea of language that it incorporates captures and synthesizes elements typical of the Zeitgeist of that century - one that witnessed many significant social changes and monumental advances in science. But it was also a period of mind-blowing contradictions. Slavery in its historical form was in its last throes, but the industrial revolution reinvented it in the form of hordes of manual workers, among them young children, being forced to work long hours earning low wages in factories that had sprung up in different parts of Europe and North America in the wake of the industrial revolution. The European colonies in Africa, Asia and South America did gain their political independence; but, alas, the old form of imperialism only gave way to a new one, this time camouflaged as economic imperialism and so-called 'soft power', exercised over the weak in subtle and subterranean ways, but equally nefarious and deleterious, all the same.

When we say that the concept of language that is encapsulated till to date in most theories of language bears all the hallmarks of the $19^{\text {th }}$ century mind-set, what we have in mind are such widely taken-forgranted contemporary ideas as that a language is by and large confined territorially (and is ideally considered coterminous with it), that there are speakers of that language that can be considered its legitimate 
'owners' in some sense akin to a birthright (call them 'native speakers' if you like), that a given language can be clearly distinguished from every other language spoken in contiguous territories, that languages can be considered entities practically closed unto themselves (i.e., the structuralist prized notion of 'cloture') and invariably drawing their élan vital from within its own entrails, and so on and so forth. It does not take one a long stretch of one's imagination to see that all or most of these postulates follow from and are indeed encapsulated in what had become a slogan, indeed a war cry, of those who upheld the principle of nationhood and its inviolability, especially in the 19th century, but dating back much earlier: 'Ein Volk, ein Reich, eine Sprache' (One people, one nation, one language). It was by invoking this principle that Adolf Hitler found it perfectly within his rights to invade Austria and annex it.

The problem with such a view of language - that was, let us not forget, very much in sync with the aspirations and beliefs of the period in which it was nurtured - is that, barely a century or so on, the world has changed in ways that could hardly have been envisaged in those days. Now, there is one unargued assumption about the science of language that stands in the way of our increasingly felt need to rethink some of those founding credos. It is the widespread belief that, insofar it is a full-blooded science, linguistics is designed to produce universal truths, valid for all times and climes. In our all-out eagerness to promote this founding principle at any cost, we often forget that language is over and above everything else a social product(and so too is the very business of thinking about it — in fact it cannot help being so), a fact unfortunately obscured and sidelined thanks to our obsession with the idea that it is a natural phenomenon, a gift of Nature. Just as Mother Nature is there forever, so too are its gifts, it is held. From there it is but a short step to conclude that, being a gift of Nature, language stays just the same in its essence through thick and thin (changes, if any, being only superficial), immune from fluctuations in the social circumstances that attend on it.

But there is a crucial snag in this otherwise glib argument. What is unquestionably true is the fact of the faculty of language being part of man's very nature (Although nothing prevents us from speculatively entertaining the idea that, given the evolutionary theory, language 
faculty itself may one day morph into something incredibly more agile and versatile, as yet beyond our wildest imagination - just as the apes and orangutans that preceded us in the evolutionary chain had little or no language faculty comparable to ours and, presumably, had no idea of what their great great grandchildren were one day to have at their disposal!

Now, what does not at all follow from the idea of language faculty being part of human nature is the idea that this or that specific language is also a gift of nature. Rather, languages in their individuating sense (as opposed to language faculty in its abstract sense) can very well be conceived of as social products, the results of a prolonged activity spanning several generations of speakers cooperatively working together in order to sculpt them into their current stage of development. Actual, living languages are used by people for talking to one another, not soliloquizing, as the concept of speech would seem to idealize. As Halliday (1974: 17) put it tersely:"[A] speaking man doesn't talk; men talk".

\section{The situatedness of all our reflections about language}

Even if one were to remain stubbornly unconvinced about the essentially social nature of language, what one cannot, in all seriousness, challenge is the idea that our thinking about language, the way we theorize it, is invariably situated in time and space. The best proof for this lies in the indisputable fact that, as one traces the history of thinking about language through the centuries, one cannot fail to notice the presence of 'reigning metaphors' that help distinguish one period from another. These reigning metaphors (Lakoff and Johnson, 1980) are furnished by the academic discipline that seems to have been at the pinnacle of glory and prestige at that specific moment in history. Thus, towards the middle of the 19th century, when Charles Darwin became a household name, there was a sudden resurgence of the metaphor of language as a living organism, reflecting the growing prestige of biology, evolution and all the rest. Languages could be seen as related to one another through the prism of kinship terms acting originally as metaphors, but soon taking on all the literal spinoffs and consequences thereof. 
When that biological view of language gained a fresh lease of life (the metaphor itself is as old as the ancient Greeks) under the auspices of 19th century Victorian morality, things took an ugly turn, as people (including many scientifically-minded linguists) were quick to denounce the newly identified pidgin languages - discovered somewhere around the middle of the $19^{\text {th }}$ century (cf. Kaye and Tosco, 2001) as aberrations of some sort for the simple fact that they seemed to break the ethical code by being born out of cross-fertilization, being "bastard" children with no noble lineage. The authors just referred to even go to the extent of trying to justify their option to invest in the study of these 'aberrant' phenomena on the grounds that it may "make significant contributions to the studies of 'normal languages' in terms of evolution, acquisition, and description, just as neurolinguistics, which attempts to account for the 'abnormal language behavior' of brain-damaged patients, can help us gain insights into the 'normalcy' of the intact human brain and the resulting language acquisition device which yields the miracle of language" (Kaye and Tosco, 2001: 8). As I wrote in a review of that book (Rajagopalan, 2005a: 116):

The truth of the matter is that terms like normal and abnormal are generally understood as value-laden and, no matter of how hard one may try to deny it, the use of these terms is ideologically problematic. Suffice it to recall that, towards the end of the nineteenth century, we find Max Müller, the great German indologist and linguist making the astounding claim 'Es gibt keine Mischsprache' (in English, 'There is no such thing as a mixed language'), not realizing, of course (or so one would hope), that fear of the loss of the putative 'purity' of individual languages that such claims harbour is part of a wider ideological agenda that also spurns miscegenation, thereby endorsing the putative purity of races.

The metaphor of evolutionary biology was in turn replaced by chemistry, physics and so forth. This was particularly evident in the realm of linguistic semantics where metaphors like atoms and molecules of meaning, alongside entropy etc. became commonplace. Our own times have witnessed an influx of metaphors inspired by the digital revolution currently taking place, giving rise to the metaphors of cutting and pasting, deleting, etc. What is important not to miss about these new metaphors that follow one another in succession is that (a) they are not just ornamental; rather, they help mould the forms of thinking 
that one conducts through them, affecting in significant ways the final outcomes and (b) they underscore the fact that the very science of language progresses in tandem with what happens outside the walls of academia and is influenced in ways that are often undreamt of by experts. A most convincing argument in support of this last point is Erickson (2004)'s thought-provoking speculative suggestion that Saussure's ground-breaking recommendation to separate synchrony from diachrony against our gut feeling that no language ever stops undergoing change through time may have been spurred on by the enormous success of the Lumière brothers who had, in the latter half of the 19th century, invented the art of cinematography and thereby proved that it was possible to create the sensation of movement (diachrony) through a quick succession of still frames (synchrony).

\section{Putting back the communicative horse before the language cart}

An abiding myth in our theorizing about language is the idea that it is the prior availability of a common language that makes any sort of communication possible between two persons. As I have argued elsewhere (Rajagopalan, 2001: 17), it is precisely the other way around. What makes it possible for two persons to engage in a fruitful dialogue with each other is a willingness to do so, being favourably disposed to the idea of establishing a working rapport with each other, rather than their sharing a common language code beforehand. In other words, language is not the cause; it is the consequence. Unfortunately, both laypersons and many experts have fallen into the trap of placing the cart before the horse when it comes to theorizing the relation between language and communication.

Putting communication - as a real world activity instead of language as an abstract object - front and centre in our quest for getting to grips with what is going on in the world today as globalization sweeps through all sorts of barricades erected in its way by parties with vested interests in the old order may turn out to be one useful starting point here. Among other things it may help us find a way out of the embarrassing spectacle of languages defying many of our time-honoured patterns of its spread, growth, transformation and 
intermingling in the face of hitherto unimaginable challenges (as well as opportunities) that the world poses today.

The constant intermingling of languages, nowadays often referred to as hybridization or the ecology of language(s) has long been known to researchers. But so long as they were restricted to the frontier regions of nation-states, they could somehow be sidelined or swept underneath the carpet and even dismissed as strictly 'borderline' cases whose existence did in no way impinge on what could be claimed about what could otherwise be considered the norm. Even here, occasional findings that defied the practice were cleverly set aside after the ripples that they had initially caused gradually died down. This was what happened to a most memorable, groundbreaking finding by Emeneau in a paper published way back in 1956 titled 'India as a linguistic area' in which in he drew attention to what he described as "the diffusion of linguistic traits across genetic boundaries" (Emeneau, 1956:3), something that was and continues to be a veritable mind-boggler to one wedded to the idea of language as a living organism of sorts with its own pedigree and kinship relations. As Khubchandani wrote:

Literate societies generally treat language as an autonomous system with its distinct history and tradition. Speech activity, however, as an ongoing process responding to a variety of communication settings, is as much a product of environment as of tradition.

\section{Form vs. Function conundrum and its many spinoffs}

The difficulty in appreciating the situatedness of our theoretical reflections is also underpinned by the age-old problem of 'form vs. function' that linguists, among others, have had to contend with for years and keep surfacing every now and then. Now, clearly there are powerful arguments supporting both sides. The very fact of the issue's longevity would bear this out. But the problem I would like to address here is downright practical: what sort of narrative about the origin of language and the way it is used in real life does either side of the controversy present us with?

According to one narrative, the one used by those who support the argument that it is the form that should get precedence over function and not the other way around, the humans morphed from the speechless apes 
to become speaking animals, thanks to evolution. Once they discovered that they were invested with its unique faculty, they wondered what possible use they could profitably put it to. It did not take our early ancestors very long before they realized they could let one know what passed through their minds. Or, put it more precisely, they discovered language could be used to communicate.

The alternative narrative that their opponents, that is to say, those who claim that it is communication where we should look for the start, seem eager to present to us runs somewhat along following lines. Thanks to their gregarious nature, humans discovered very early that they could be stronger by bonding together as a group and defending themselves against their common enemies. They also learned early on that the best way to do this is by planning their defence strategies ahead and be prepared for emergencies instead of having to come up decisions at the eleventh hour. To do this, they found they had to somehow communicate thoughts to one another. To put more meat on the bones of this Gedankenexperiment, they started doing this initially through gestures and monosyllabic grunts and cries, and finally to fully-fledged languages the way we know them today, a long-winded process that probably took several evolutionary years and stages. In other words, human language came into being when our early ancestors perceived the advantage of bonding together and doing it efficiently through the use of a reliable semiotic means, perfected through passage of time and sculpted to meet the needs as they presented themselves along the way.

The difference between the two narratives presented above could not be any starker. The first one, that seems to underwrite the case presented by defenders of the form-first theory, is somewhat reminiscent of the opening scene of the famous movie 2001 Space Odyssey where an ape, probably our last pre-human ancestor, discovers by sheer accident a femur bone buried in the sand and equally accidentally also discovers that he could use it to fend off enemies and even bludgeon them to death. The only difference is that, in the film, the ape discovers the first weapon of warfare ever to be used, in our Gedankenexperiment illustrating the form-first thesis, it is language. What they have in common is that they both discover the form first and then figure out a way to put it use in their best interest. 
Here is a quote from Chomsky (1984) who is undoubtedly one of form-first approach's strongest contemporary champions:

QUESTION: As I understand, language has an innate biological basis. Its use, however, is social. What do you think of the social functions of language? Is it primarily an instrument of communication?

CHOMSKY: I think a very important aspect of language has to do with the establishment of social relations and interactions. Often, this is described as communication. But that is very misleading, I think. There is a narrow class of uses of language where you intend to communicate. Communication refers to an effort to get people to understand what one means. And that, certainly, is one use of language and a social use of it. But I don't think it is the only social use of language. Nor are social uses the only uses of language. For example, language can be used to express or clarify one's thoughts with little regard for the social context, if any.

Chomsky has systematically dismissed communication as the primary function of language and lately sought to distance it from the social use of language. Instead he would rather contemplate language as an abstract object that is at the service of the homo sapiens.

The picture that emerges from the Gedankenexperiment is, nevertheless, analogous to the opening scene of 2001: Space Odyssey and is the best captured by the following imaginary situation: someone discovers a brick lying by the roadside and wonders what they can best do with it. They can look for more bricks lying around in the hope they would one day be able to build, maybe a wall, with them. Or they can keep the brick ready at hand in the hoping of coming across their nextdoor neighbor whom they hate and use it to knock him out once and for all; or they can, who knows, daub the brick with a coat of glittering gold paint and make a quick buck by beguiling some gullible bloke to buy it! The sky is the limit for this long list of ingenious uses!

It is easy to pretend that they are all equally viable alternative uses of a block of bricks found by the roadside and argue that it makes no sense to argue that the primary purpose of a brick is to build a wall, and only marginally, to be used as a weapon to hit someone, and even more marginally (and whimsically, one should add) to be used to trick someone. Likewise, it is easy to pretend that any and every imaginable function of language other than that of communication is just as good 
and just as important as any other. These other alternatives might include such things as solving crossword puzzles and painting graffiti on walls and what have you. And in our times of fake news disseminated through troll factories language may even be characterized as a means of disinformation! But to use such a dismissive line of argumentation in order to overthrow the time-honored notion that language is the primary and most efficient means of communication in order to bolster at any cost one's dearly-held obsession that what matters in the end is the object called language, not what one does with it, is to deflect one's attention from serious reasoning rather than engaging in it head on.

This is how Law (2003:8) reacts to the customary practice adopted by the linguist:

\begin{abstract}
Linguistics entails a way of thinking which is abstract, analytical and systematic. To think about language in this manner we have to stand back from it and reify it, making it into an object 'out there'. That is a paradox, for language cannot exist without us. Yet to carry out all those analytical procedures that we take for granted - to think of language as a system independent of the speaker, or to divide a word into morphemes, or to represent a sentence diagrammatically - is to take a step away from the reality of our daily experience. This process of distancing ourselves from the phenomena is so much a part of our modern way of thinking that we do so unquestioningly, totally accepting the inherent paradox.
\end{abstract}

It is perhaps opportune at this juncture to enter an important caveat here. When Law generalizes her comments about linguistics what she has in mind is the area of investigation since its inauguration as a discipline, announcing its modern, "scientific" turn that has somehow become synonymous with it ever since. It should come as no surprise therefore that much of what she says about Linguistics applies, mutatis mutandis, to many, in fact most, of the so-called social sciences where one notices a systematic tendency to keep at bay all factors attendant on a given phenomenon so as to contemplate it in its splendid isolation in utter disregard for the fact that such factors impinge on the phenomenon in question and, are often, even constitutive of it in fact. Let us not forget that all this is done under the auspices of a certain view of science, not science itself, insofar as it is a quest for unravelling the enigma of everyday phenomena. The decision to slice reality one way rather than another, or for that matter, to slice it at all to begin with should not 
confused with the enterprise of science itself but the specific paradigm of it that rules the roost at any given moment in history.

\section{Linguistics and the way it narrates its own history}

The moment one mentions the word history in the context of judging the claims in linguistics, one is obliged to bring up for discussion that linguists themselves, in sync with fellow scientists, are loath to even consider worth spending their precious time. In a paper written more than a decade ago (Rajagopalan, 2005b: 100), I quoted the following words from an introductory textbook on linguistics;

The facts of linguistic science in 1935 may be different from the facts of linguistic science in 1960, which in turn may be different from the facts of linguistic science in 1980. But what remain essentially unchanged and continually productive are the process of inquiry that we define as linguistics or, if you will, the linguistic enterprise. (Postman and Weingartner, 1966: 5)

\section{And I went on to comment:}

In other words, part of what is meant when its practitioners call linguistics a science is that the kind of knowledge it produces is timeless. Furthermore, it is believed to be equally well applicable to all cases, no matter how geographically or culturally diverse they may happen to be from one another. (Rajagopalan, ibid.)

Adding, a little later,

Just as modern chemistry is anxious to distance itself from alchemy from which it historically evolved, so too modern linguistics will have no trucks with philology which preceded it. The 'linguistic enterprise' consists, so it is claimed, in a certain attitude to the very business of inquiry, not in this or that specific finding it may provisionally arrive at any given moment. Linguistics is a science in that it aims at overarching explanatory frameworks, where all individual cases past or present or the ones yet to present themselves can be neatly accommodated. (Rajagopalan, ibid.)

Modern Linguistics has been averse to history and this attitude manifests itself at different levels. It was present at the time of de 
Saussure's inaugural decision to relegate diachrony to the backburner and privilege synchrony, all in the name of science. It was present Chomsky's decision to espouse what its critics have berated as the "instantaneous acquisition of language" i.e., the idea so dear to Chomsky and his acolytes that there are no progressive stages in language acquisition by a child; it is, to quote the famous remark by Chomsky (1993: 519) himself, "not really something that the child does; it is something that happens to the child." (italics added). When it comes to tracing and recounting the history of their science that linguistics occasionally stray into, it is always done in black and white (with no shades of grey in between). As Aarsleff (1970: 570) famously wrote in his scathing review of Cartesian Linguistics (Chomsky, 1966),

Transformational generative grammar was linked to antecedents in the $17^{\text {th }}$ and $18^{\text {th }}$ centuries, both as a matter of intellectual interest and to serve the purpose of polemics against its own immediate predecessor in linguistics, the tradition which can be called Bloomfieldean - a tradition which had gone out of its way to show contempt for the work which Chomsky was now raising to a position of respect and admiration.

Note that Aarsleff was, contrary to what many of his early readers hastily concluded, critical not only of the way Chomsky cherry picked amongst his predecessors, sorting them to the good guys and the bad ones, but equally critical of many other linguists-cum-historians across the board, irrespective of their stripes, who have recounted the history of their discipline in ways most convenient to their own specific agendas.

In effect, then, the message that finally comes through after these incursions into the history of the field of enquiry is: Overall, when all is said and done, the history of past thinking about language is littered with the debris from misguided attempts to delve into the mystery of language - though, occasionally, one should not be surprised to find a genius or two, many of them lost somewhere in its annals who had amazingly original and anachronistically 'modern' and fullbloodedly 'scientific' insights that unfortunately went unheeded by his contemporaries or failed to outlast their own brief passage on the face of this earth. 


\section{The situatedness of language research, once again}

The discussion in the last few paragraphs takes us, once again, back to the theme of the inevitable situatedness of research, especially so in social sciences, and hence, linguistics.

Whether one is willing to concede the point or not, some of the most cherished concepts that form the bedrock of its theoretical apparatus are responsive to the way the reality around those who sculpted those concepts and even more importantly the way they perceived it. We have already seen how many of those concepts so fundamental to our present-day thinking about language were forged in the $19^{\text {th }}$ century. One distinctive feature of the mindset of that period was that concepts were invariably thought up in an all-or-nothing fashion, with the help of binary logic. One either spoke language $x$ or language $y$-but never both, not the least with the same command. This was underwritten by the argument that one had to be the native-speaker of this or that language, by virtue of the sheer fact of having been born in this or that cultural-cum-linguistic milieu. This in turn rested on the assumption that, thanks to the inward-looking foreign policy practiced by many nation-states as part of the then popular geopolitics, the inhabitants of a given nation-state could be credited with belonging to the same culture that told them apart from the inhabitants of every other nation-state.

In order to see how these 'self-evident truths' have no universal value whatsoever, it is sufficient to recall that there always was an alternative way of looking at the same phenomenon, but one that was somehow suppressed, one must assume, owing to pressing political agendas that marked the epoch. As Wright described these alternative approaches,

In scholarship, there have been two divergent positions on the nature of language. The first derives from the scientific tradition that holds that there is a 'real world 'out there' that can be understood and described objectively in language. It finds expression in positivism in the nineteenth century and some strands of structuralism in the twentieth century. The second is rooted in the belief that speakers/writers are autonomous subjects who, through free will, co-construct meaning with their interlocutors. 
And she goes to cite the following words of Halliday (2003: 99-100) to bring out the differences between the two in their starkest terms:

In the former, linguistics is part of philosophy and grammar part of logic; in the latter, linguistics is part of anthropology and grammar is part of culture. The former stresses analogy; is prescriptive, or normative, in orientation; and concerned with meaning in relation to rhetorical function. The former sees language as thought; the latter sees language as action.

Unlike thought (itself thought of in the abstract!), action is always situated - indeed it cannot help being situated. Furthermore, it is always sensitive to what is trending in its 'context of situation' to use that classical Halliday turn of phrase.

\section{The 21 st century and centuries ahead: reading the tea leaves}

The opposition 'language-as-thought vs. language-as-action' gives us a clue as to what may be in store for linguistics in the current century and the ones ahead. In a fast changing world such as the one currently live in, it seems to me that a linguistics that refuses to take into account the circumstances changing under its very nose is doomed to run aground for reasons not too far-fetched to enumerate, not the least urgent of which is the threat of its becoming obsolete for progressively losing touch with reality. With globalization forging ahead the way it is (despite growing cries in some quarters for turning the clock back to the days of chest-pounding nationalism!), a number of our time-honored concepts, among which, that of nation-states, isolated cultures, and so forth, it is high time we linguists went back to the drawing board and checked to see if the tools we have in our box of concepts are still adequate to deal with the new challenges that present themselves and the ones that seem poised to turn up in the not-so-distant future.

The most salient hallmark of our times is the fluidity of entities whose conceptual identity was, until not very long ago, considered stable and nonnegotiable. Identities were never discrete and durable the way they were taken to be, but that did not deter many scholars to go ahead with a glib notion of inalienable identities under the excuse 
that problems of ill definable identities and borderline ones could be set aside as marginal. But when the concepts of nation, state, polity, people, and so forth were tied to and reinforced one another it was relatively easy to entertain the illusion that they remained unchanged over long stretches of time. But what we are witnessing today is the breakup of all these concepts and, as their integrity melts away, what we are left with is a constant realignment of the order of things. Needless to say, this calls for a thorough overhaul of our theoretical baggage, not a partial repair here and there.

A research project worth pursuing in our days of rapid changes occurring all over the place is just how language is being reconstituted today to suit the enormous challenges we face even as we continue using it to the best of our capacities and possibilities, rather than marvel at how ordinary people are coping with them while making use of the language they always already had at their disposal (a feat, which, let us recognize it once and for all, they in fact are increasingly finding it difficult to pull off). What factors are directly impinging on the way it is shaping up in answer to these challenges and what profound changes are they promoting in what languages are evolving into (Rajagopalan, 2015). Alternatively, is the time not ripe to seriously confront the concept of 'languaging' and incorporate that notion which has been around for quite some time (cf. Maturana, 1978) as its central focus of our investigation into language and the way we conduct our daily lives for the 20th centuries and ones ahead?

\section{Acknowledgement}

I am grateful to the CNPq for awarding me a research grant $n^{\circ}$ 302981/2014-4.

\section{References}

AARSLEFF, Hans. 1970. 'The History of Linguistics and Professor Chomsky.' Language. Vol. 46. No. 3. p. 570-585.

CHOMSKY, Noam. 1966. Cartesian Linguistics: A Chapter in the History of Rationalist Thought. New York: Harper \& Row. 
. 1993. 'A minimalist program for linguistic theory.' In: HALE, Kenneth \& KEYSER, Samuel Jay (eds.). The View From Building 20: Essays in Linguistics in Honor of Sylvain Bromberger. Cambridge, Mass: MIT Press.

EMENEAU, Murray Barnson. 1956. 'India as a linguistic area.' Language. Vol. 32. No. 1. p. 3-16.

ERICKSON, Frederick. 2004. Talk and Social Theory. Cambridge: Polity.

HALLIDAY, Michael. 1974. 'Language as social semiotic: toward a general sociolinguistic theory.' In: Makai A. and Makai V. B. (eds.). The First LACUS Forum 1974. Columbia, SC: Hornbeam Press, p. $17-46$.

2003. On language and linguistics. London: Continuum.

HUTTON, Christopher. 1996. 'Law lessons for linguists? Accountability and acts of professional classification.' Language and Communication. 16. 3. p. 205-214.

KAYE, Alan S. and TOSCO, Mauro. 2001. Pidgin and Creole Languages: A Basic Introduction. Muenchen: Lincom Europa.

KHUBCHANDANI, Lachman M. 1991. 'India as a sociolinguistic area.' Language Sciences. Vol. 13. No. 2. p. 265-288.

LAKOFF, George and JOHNSON, Mark. 1980. Metaphors We Live By. Chicago: University of Chicago Press.

LAW, Vivien. 2003. The History of Linguistics in Europe: From Plato to 1600. Cambridge: Cambridge University Press.

MATURANA, Humberto R. 1978. Biology of Language: The Epistemology of Reality. In: MILLER, George A. and Elizabeth Lenneberg (eds.). Psychology and Biology of Language and Thought: Essays in Honor of Eric Lenneberg. New York: Academic Press, p. 27-63.

OSIATYNSKI, Wiktor. 1984. On Language and Culture: Noam Chomsky interviewed by Wiktor Osiatynski In Osiatynski, Wiktor (ed.). Contrasts: Soviet and American Thinkers Discuss the Future. London: MacMillan, p. 95-101.

POSTMAN, Neil and WEINGARTNER, Charles. 1966. Linguistics: A Revolution in Teaching. New York: Dell Publishing Co. Inc.

RAJAGOPALAN, Kanavillil. 2001. 'The politics of language and the concept of linguistic identity.' CAUCE, Revista de Filología y su Didáctica. $\mathrm{n}^{\circ} 24$. p. 17-28.

. 2005a. 'Review of Kaye and Tosco, 2001.' Word. Vol. 56. $\mathrm{n}^{\mathrm{o}} 1$. p. $115-119$. . 2005b. 'The language issue in Brazil: when local knowledge 
clashes with expert knowledge'. In: Suresh Kanagarajah (ed.). Mahawah, NJ: Lawrence Erlbaum Associates. Reclaiming the Local in Language Policy and Practice. p. 99-122.

. 2015. 'Language in our postmodern times and the pressing need to find novel ways of conceptualizing it'. In: Gerda Haßler (ed.). Metasprachliche Reflexion und Diskontinuität. Wendepunkte - Krisenzeiten - Umbrüche. Münster: NodusPublikationen. p. 296307.

WRIGHT, Sue. 2015. 'What is language? A response to Philippe van Parijs'.Critical Review of International Social and Political Philosophy. Vol 18. No. 2. p. 113-130.

Recebido em: 18/04/2018

Aprovado em: 10/10/2018 